\title{
What is said and what is done
}

\author{
Arkalgud Kumar ${ }^{1}$
}

${ }^{1}$ AIIMS

December 31, 2020

\begin{abstract}
Invasion in cardiac surgery is maximum when cardiopulmonary bypass $(\mathrm{CPB})$ is used. The period is of no consequence as all complications such as Bleeding, Cerebral. Renal, vascular and Inflammatory responses are initiated when CPB is used. The term minimally invasive is therefore most inappropriate when CPB is used irrespective of the type of operation, incision, cosmesis, and use of sophisticated technology.This editorial highlights the misuse of the term Minimally invasive cardiac surgery.
\end{abstract}

\section{Hosted file}

Text.pdf available at https://authorea.com/users/386514/articles/501972-what-is-said-andwhat-is-done 